\title{
ONGOING RESEARCH ON SEISMIC SAFETY ASSESSMENT
}

\author{
RAIMUNDO \\ DELGADO \\ Full Professor \\ FEUP \\ Porto - Portugal \\ JOÃO GUEDES \\ Auxiliary Professor \\ FEUP \\ Porto - Portugal
}

\author{
ANÍBAL COSTA \\ Full Professor \\ UA \\ Aveiro - Portugal \\ XAVIER ROMÃo \\ Assistant \\ FEUP \\ Porto - Portugal
}

\author{
ANTÓNIO ARÊDE \\ Auxiliary Professor \\ FEUP \\ Porto - Portugal \\ PEDRO DELGADO \\ Assistant \\ ESTG - IPVC \\ Viana do Castelo - \\ Portugal
}

\author{
NELSON VILA \\ POUCA \\ Auxiliary Professor \\ FEUP \\ Porto - Portugal \\ PATRÍCIO \\ ROCHA \\ Auxiliary Professor \\ ESTG - IPVC \\ Viana do Castelo - \\ Portugal
}

\begin{abstract}
Research on seismic safety assessment has been the centre of great interest among the scientific community in recent years. Although the devastating impact of earthquakes on current society should be incentive enough to increase research on seismic safety assessment, the development of more realistic nonlinear mechanical behaviour models and the continuously increasing computation capabilities are paramount factors contributing a great deal to the increase of such interest.

The paper will present some of the current trends of scientific research on seismic safety assessment, emphasizing the work currently being developed at FEUP on this domain. The paper will mainly focus studies addressing the seismic behaviour of structures and also different types of methodologies for seismic safety assessment, ranging from more simplified to more complex methods.

Reference will also be made to experimental research being currently carried out at FEUP and will serve as support for the development of numerical models simulating the effects of different seismic strengthening techniques.
\end{abstract}

\section{INTRODUCTION}

The enormous impact of earthquake effects on current society has induced an increase of the research on seismic safety assessment, which profits from the exceptional developments on computational and experimental tools of recent years.

Several strategies to assess the seismic safety of structures have thus being developed over the years, namely methodologies with some complexity and generality, where realistic nonlinear mechanical behaviour models and the explicit evaluation of the probability of collapse of the structure are included.

These accurate methodologies allowed for a better understanding of the seismic behaviour of structures and, at the same time, the development of a new generation of seismic structural codes such as the Eurocode 8 (EC8) [1], in which a large number of provisions that must be conveniently calibrated are included. In this paper, some topics included in Part 3 of Eurocode 8 (EC8-3) [2], addressing the provisions for the evaluation of the seismic performance of existing structures, will be discussed.

With the development of experimental tools it is now possible to better understand the behaviour of structural elements under cyclic loads, a crucial issue for the numerical evaluation of the seismic response of structures under earthquakes. As an illustration of this type of capabilities, a general description of the experimental setup 
existing at the Laboratory of Structural and Seismic Engineering (LESE) of the Faculty of Engineering of the University of Porto (FEUP) and a sample of recently obtained experimental results is presented herein.

With such increasing abilities, one can expect the development of new perspectives for seismic design. In the final part of the paper, a seismic design scenario for the future, where fully nonlinear dynamic analysis of structures and an accurate seismic safety format is involved, is presented, along with several key points for its implementation.

\section{STRATEGIES FOR SEISMIC SAFETY ASSESSMENT}

Several methodologies to assess the seismic safety of structures are currently being used, ranging from the more complex and general to the more simple and easy to apply. The latter usually involve more assumptions and simplifications in opposition with the more general methodologies that try to reproduce reality as close as possible.

The more general methodologies for seismic safety assessment aim to explicitly deal with any probability distribution of the seismic action, to evaluate structural seismic effects using a dynamic nonlinear analysis and to consider the "strength" capacity in a probabilistic way, by means of a probability distribution function, in order to evaluate the probability of collapse of the structure.

One of these methodologies, which will be presented herein, has been developed at the beginning of the 1980s [3-5], and continues to be updated [6], thus showing to be an increasingly powerful tool for the calculation of seismic risk of the structures considering, namely, the enormous increase of computational capabilities. In addition, results obtained by this method may provide a sound support for calibration of other methods involving simplifying assumptions. The fact that this methodology represents a more general approach for seismic risk assessment may imply a larger number of structural analyses. Nonetheless, this number may be reduced if certain simplifying assumptions are considered, similarly to what happens in other methods. Such is the case of the SAC/FEMA approach proposed by Cornell [7], in which assumptions for the hazard, the probability density function of the capacity, and for the relationship between inter-storey drift demand and spectral acceleration are proposed. In this approach, a simple and easy to compute closed form is obtained for the probabilistic risk assessment computation, eliminating the need to perform a numerical integration, as required in the methodology proposed herein.

Another type of reliability approach that bears some similarities with the previous methods is that based on the definition of the fragility curve (see for example [5]). In this approach, given that structural demand samples for increasing levels of seismic intensity are available, the fundamental idea is to perform the computation of the probability of failure for a convenient number of intensity values, irrespective of the probability of occurrence of such intensity values. This set of probability values defines the previously referred fragility curve.

\section{PROBABILISTIC SEISMIC SAFETY EVALUATION}

In order to evaluate the structural safety with an accurate and general procedure, it is necessary to calculate the probability of collapse, given by the convolution of the probability distribution of the demand with the probability distribution of the capacity [3]. To obtain the demand probability distribution it is necessary to know the probability distribution of the seismic action and define the so-called vulnerability curve, a nonlinear function that relates the seismic action with the action effects. Therefore, to establish the vulnerability curve, the seismic response of the structure for increasing levels of seismic intensity must be computed to obtain the desired response value for each one of these intensity levels. This curve relates seismic intensity with an estimator value, e.g. a maximum or an average value, of the control parameter chosen to describe structural response. Assuming that the structure under study is, for example, a simple framed structure made out of beams and columns, the control parameters could be defined, for example, by the maximum ductility demand at the member ends. For seismic safety assessment, these can be adopted as control parameters bearing in mind that, for such type of structural elements, larger strains and larger nonlinear incursions will develop in regions close to the extremities of the members. Without loss of generality, this demand type will be selected hereon for the presentation of the method. 
In order to take into account the stochastic characteristic of earthquakes, i.e. the record-to-record variability, several accelerograms, either real or artificial, must be used to compute structural demand. When artificial accelerograms are used, they must be synthesized in a random manner, in order to match the response spectrum that characterizes earthquake ground motions at the site under study.

For the selected seismic intensity values, the maximum ductility demand at the control sections must then be obtained for each accelerogram of the select set. Then, for each intensity level, the average value of the maxima of the demand is computed, thus defining the previously referred demand estimator value for the vulnerability curve. A polynomial function can then be fitted to this set of average demand values, along with their corresponding intensity levels, to yield the vulnerability function of each section, as illustrated by curve number 3 in Fig. 1.

Among the several possibilities that can be selected to define the intensity of an earthquake, the peak acceleration value in the horizontal direction, a, is chosen hereon without loss of generality of the method. For a given region, the probabilistic distribution of these intensities should be estimated by combining i) seismological information expressed by generation models, distribution of location, magnitude and intensity of past earthquakes in the region, and ii) geological and geotechnical data, [3].

The maximum annual values of peak acceleration can then be computed using generation models based on the magnitude values and source locations observed from past earthquakes; magnitudes being transformed into bedrock accelerations by means of attenuation formula.

For a 50 years lifetime of the structure, the characteristic value of the distribution of peak acceleration, ak, is equal to the 0.95 fractile (for a return period of 975 years of return period) of the annual extreme distribution as defined by Eq. (1).

$$
F\left(a_{k}\right)=\left(1-\frac{1}{975}\right)^{50}=0.95
$$

It is considered hereon that the most important part of the distribution of peak accelerations maxima in 975 years can be defined by an extreme type I probability distribution, $[9,10]$. Thus, the distribution of the seismic action, represented as curve number 1 in Fig. 1, can be characterised by the following:.

$$
f(a)=\alpha \cdot \exp (y-\exp (y))
$$

where $y=-\alpha(a-u)$ and $\alpha$ and $u$ are the parameters that characterise the distribution.

Using the vulnerability function, a transformation of the earthquake action into the action effect in the structure is then carried out. More precisely, considering the vulnerability curve of each control section, the referred transformation can be carried out for each one of these sections, yielding the action effect distribution for each section. Considering that demand is expressed in terms of ductility, the referred transformation yields the probability density function $f_{E A}$ of the ductility demand of each control section action effect (curve 4 in Fig. 1) which also allows for the computation of the corresponding cumulative distribution function $F_{E A}$.

For the probabilistic characterisation of the capacity of the control sections, in terms of available ductility for the present case, a probability density function $f_{R}$ must be considered (curve 2 in Fig. 1). If this function is normal (or lognormal), it is sufficient to define the mean ductility $\mu_{\mathrm{d}}$ and its coefficient of variation (or their corresponding logarithms). These two parameters can be obtained either from experimental results or by means of a simulation method as can be seen in [11] where the Latin Hypercube Sampling technique was used.

Finally, considering that the collapse of one control section reflects the collapse of the structure, an admissible assumption in the case of bridges, the referred probability of collapse can be evaluated by computing the integral of the convolution function, given by Eq. (3) and represented by curve number 5 in Fig. 1. the convolution function is defined by the cumulative distribution function of the action effect (demand ductility) $F_{E A}$ and the probability density function $f_{R}$ of the capacity expressed in terms of available ductility [3, 4].

$$
C(\mu)=\left(1-F_{E A}\right) \cdot f_{R}
$$




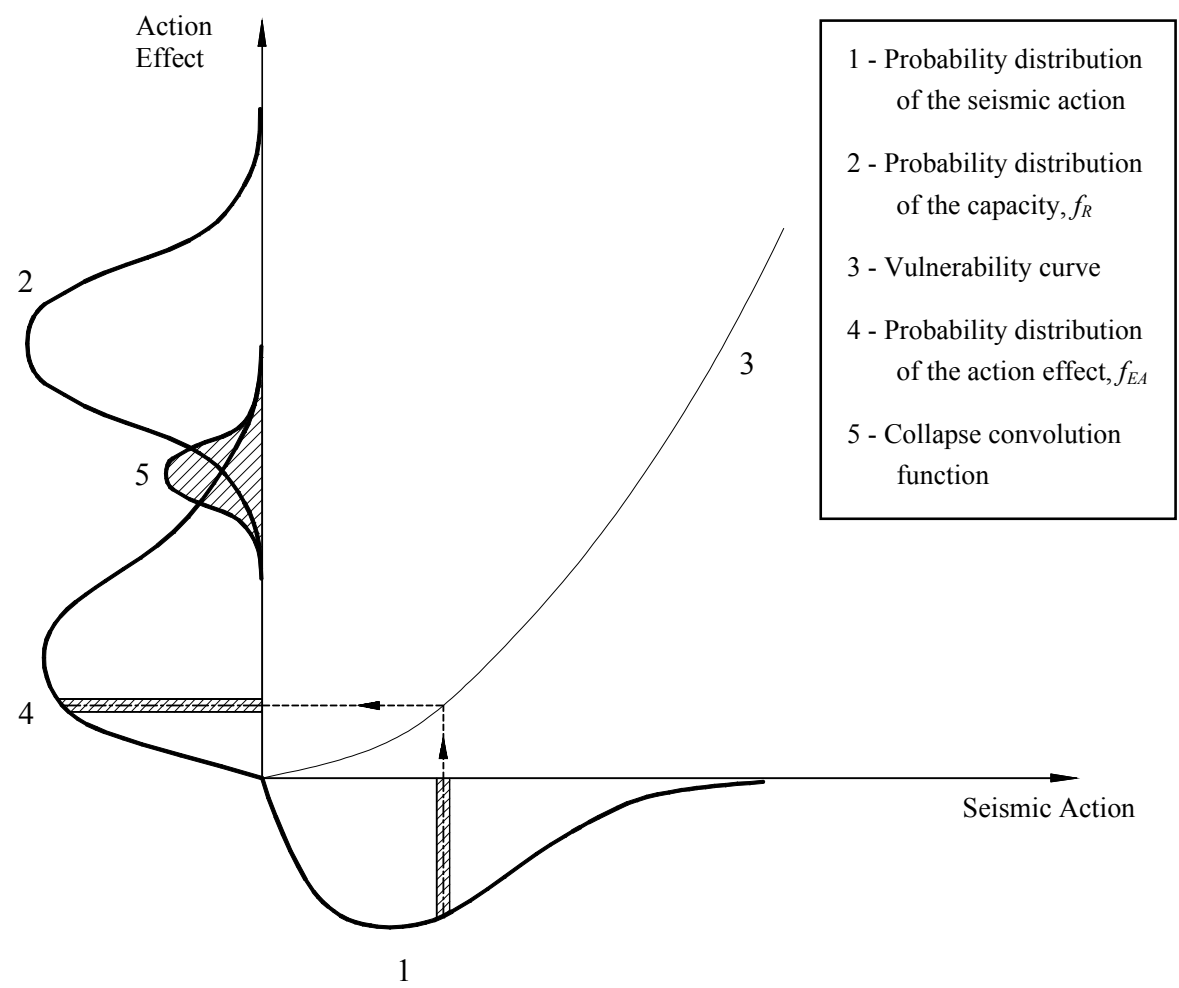

Figure 1: Graphic representation of safety assessment procedure.

\section{CODES CALIBRATION}

Earthquake engineering experts, public authorities and general public alike agree on the idea that the assessment of the seismic safety and performance of the built environment is a matter of high priority in which the development of updated and efficient structural codes plays a decisive role as is the case of the EC8. As the main objective of these documents is to define a general framework allowing the design of new structures and the evaluation of the seismic performance of existing ones, they must provide simple though accurate provisions, defined on the basis of considerable scientific and technical research. Nonetheless, careful calibration of such provisions is usually required.

In this Section, some topics included in EC8-3, addressing the provisions for the evaluation of the seismic performance of existing structures, are discussed. Although this document has been thoroughly checked for consistency, little comparative applications have been performed to date. Hence, studies addressing the assessment and validation of the code deterministic procedures are needed.

Sample results of recently performed study [13] addressing the assessment and validation of the EC8-3 deterministic procedures for seismic safety assessment, complemented using a probabilistic approach, is presented herein. The study addressed the application of the deterministic procedure for the safety assessment of two reinforced concrete one-bay-four-storeys planar frame structures of similar geometry and that were considered to be part of larger structures. The seismic safety of the structures was assessed for both deformation and strength based Limit States (LSs). For each LS, the three EC8-3 Knowledge Level (KL) conditions were also considered for safety assessment. Safety assessment for each LS and KL combination was performed using linear and nonlinear methods of analysis. In the latter case, both pushover and dynamic analysis (using artificial and real records) were used, while in the former only static analysis was considered.

In terms of the applicability of linear analysis methods, results of the selected structures showed that, for all the LSs, they failed to meet a certain EC8-3 criterion (the $\rho_{\max } / \rho_{\min }$ criterion). Therefore, linear analysis was not able to be considered for seismic safety assessment of these structures. Nonetheless, results also indicated that, for 
structures where seismic design measures were not considered in the initial design, applicability of linear analysis might be restricted to the LS of Damage Limitation (DL) only.

From the results of the deterministic assessment based on nonlinear analyses, it was possible to conclude that DL seems to be the dominant deformation LS. It can also be seen that the influence of the KL is considerably different for chord rotation and shear force capacities, the latter being more sensitive to the different KLs.

With respect to nonlinear dynamic analysis results, these lead to conclude that the type of accelerogram has a considerable influence on the deformation assessment results. Such differences are a direct result of the differences observed between the real records response spectra and the code spectrum. On the other hand, the shear force assessment results can be seen to be much less sensitive to the record type. To improve the results obtained from real records scaled for spectral acceleration ordinates, for the Significant Damage (SD) and Near Collapse (NC) deformation LSs, an alternative scaling period was also considered. This procedure provided an overall better agreement between results of the artificial accelerograms and those from real records (see [13] for additional details).

Comparative assessment between pushover and nonlinear dynamic analysis safety assessment results leads to conclude that for deformation based LSs, correlation between pushover and nonlinear dynamic analysis results is best when considering artificial accelerograms. When considering real records, agreement is best when considering the alternative scaling period previously referred. In terms of the shear force NC LS, agreement between dynamic and pushover results is much better, irrespective of the selected ground motion type. In the overall, with the exception of some control sections, push over results can be seen to be on the safe side, when compared to the results of nonlinear dynamic analysis.

With respect to the influence of the KL in the assessment results, it was found that, from the practical point of view, going from KL1 to KL2 or from KL2 to KL3 produces limited changes in the capacity values. Therefore, the need for an increase in knowledge about the materials must be carefully thought out due to the increase in work and costs that may be implied.

In what concerns the Confidence Factors (CFs) defined by EC8-3 associated to the KLs, a statistical approach was developed to assess their adequacy. The developed approach seems to confirm the existence of a consistent underlying framework justifying the EC8-3 proposed values for the CFs of KL1 and KL2. With respect to the proposed CF for KL3, the study suggests that a value of 1.10 should be used instead (see the boxed values in Fig 2 defined for the minimum number of samples of each KL).
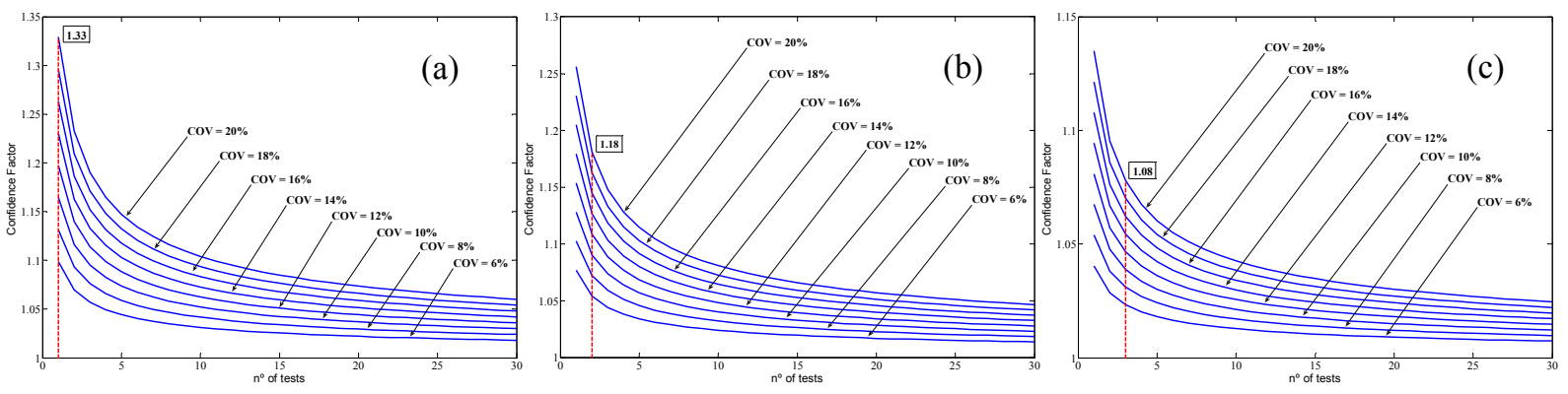

Figure 2: Upper limits of the $C F s$ for increasing values of the number of material samples $n$, a range of coefficient of variation (COV) of the material property and (1- $\alpha$ ) probability levels of (a) $95 \%$, (b) $90 \%$ and (c) $75 \%[13]$.

\section{EXPERIMENTAL CHARACTERIZATION OF CONSTITUTIVE LAWS}

The full understanding of the behaviour of structural elements under cyclic loads is crucial for the numerical evaluation of the seismic response of structures. This knowledge is essentially obtained through experimental campaigns consisting of cyclic load tests on beams and columns subjected to cyclic loads of increasing intensity, ultimately leading to the constitutive laws of these elements. As an illustration of this type of capabilities, a 
general description of the experimental setup existing at the LESE of the FEUP and a sample of recently obtained experimental results is presented in this Section.

The test setup was designed to impose cyclic horizontal top displacements with axial load and the possibility of using two orthogonal actuators with a sliding device that allows both displacements and rotations at the pier top, relative to the vertical actuator fixed to a steel portal frame.

The test setup, shown in Fig. 3, makes use of a $500 \mathrm{kN}$ actuator to apply lateral loads and a $700 \mathrm{kN}$ actuator to apply axial loads. The specimen and reaction frame are bolted to a strong floor with high strength prestressed rods. A constant axial load was applied during the tests described herein while the lateral loads were cycled, under displacement controlled conditions.
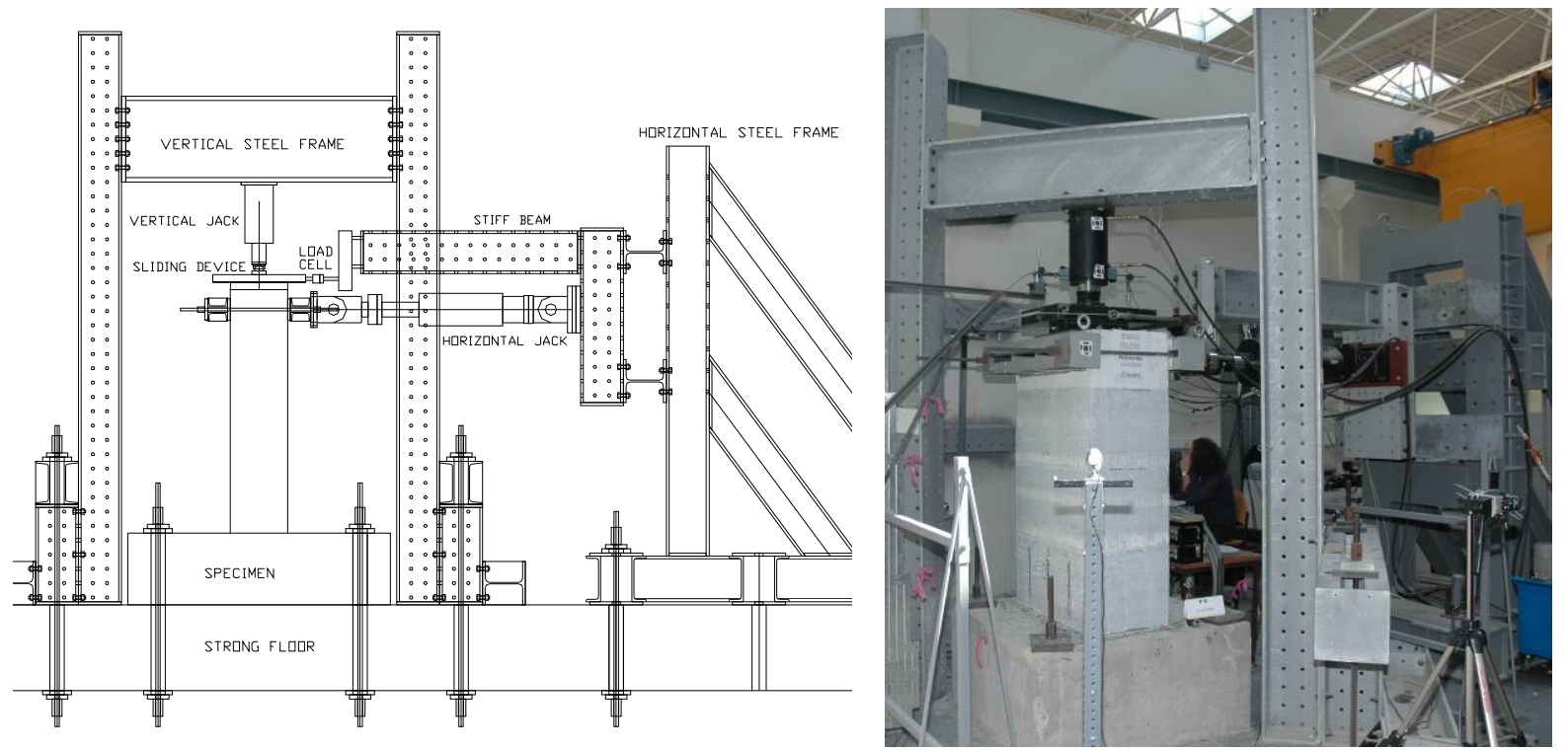

Figure 3: Schematic layout and view of the test setup at LESE laboratory.

A special sliding device consisting of two steel plates, shown in Fig. 4, was used to minimize the friction created by the axial loads. The lower plate is bonded to the specimen top, whereas the upper is hinged to the vertical actuator, allowing top-end displacements and rotations of the specimens to take place when lateral loading is imposed during the test. The upper plate is also connected to a load cell to measure the residual frictional force between the two plates. The hydraulic system of the vertical actuator was designed to keep the oil pressure constant during the tests, in order to maintain the axial force constant.

The horizontal actuator control is done using a PXI controller system from National Instruments (NI) and specifically home developed control routines based on the LabVIEW software platform (also from NI). The data acquisition is also based on another PXI system equipped with acquisition and signal conditioning cards and allows direct reading of data from strain gauges, load cells, LVDTs (Linear Voltage Displacement Transducers) and other types of amplified analogical or digital sensors.

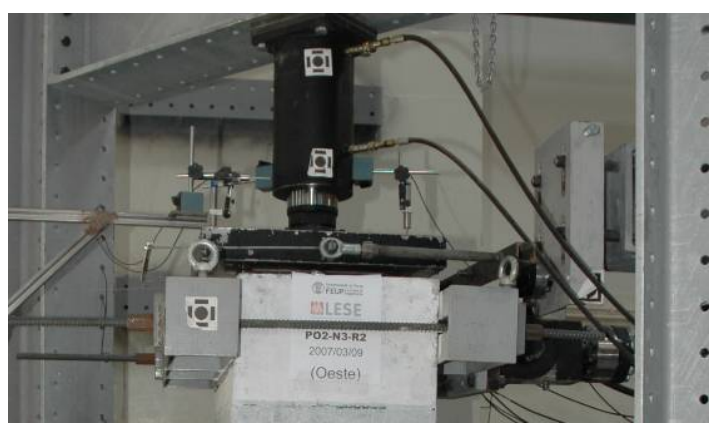

Figure 4: Sliding device used to apply the axial load. 
A sample of recently obtained experimental results for two groups of columns is presented in the following. The first group of columns consists of full rectangular section RC columns and the second group is made of hollow rectangular section RC piers. The first group of the specimens was chosen in order to reproduce several columns of the frame studied in the framework of the ICONS project and tested experimentally at ELSA laboratory of JRC at Ispra (Italy) [14, 15]. A total of fourteen full scale RC columns were tested before and after retrofitting them with different techniques. The second group consist of twelve specimens: six square hollow section RC piers with $450 \mathrm{~mm} \times 450 \mathrm{~mm}$ exterior dimensions and $75 \mathrm{~mm}$ thick walls, based on square piers tested at the Laboratory of Pavia University, Italy [16], and six rectangular hollow section RC piers of $450 \mathrm{~mm}$ x $900 \mathrm{~mm}$ (with the same wall thickness), that were tested in order to understand the influence of the cross section geometry of rectangular hollow piers on the cyclic behaviour, bearing in mind the purpose of assessing the behaviour of different retrofitting solutions.

The model schemes shown in Fig. 5 correspond to full scale rectangular section RC columns (referred as PA) and hollow rectangular section RC piers ( $1 / 4$ scale), herein referred to as PO: PO1 for square section and PO2 for rectangular section. Instrumentation to measure curvature and shear deformations was included along the pier height, because important shear deformations were expected in these tests.
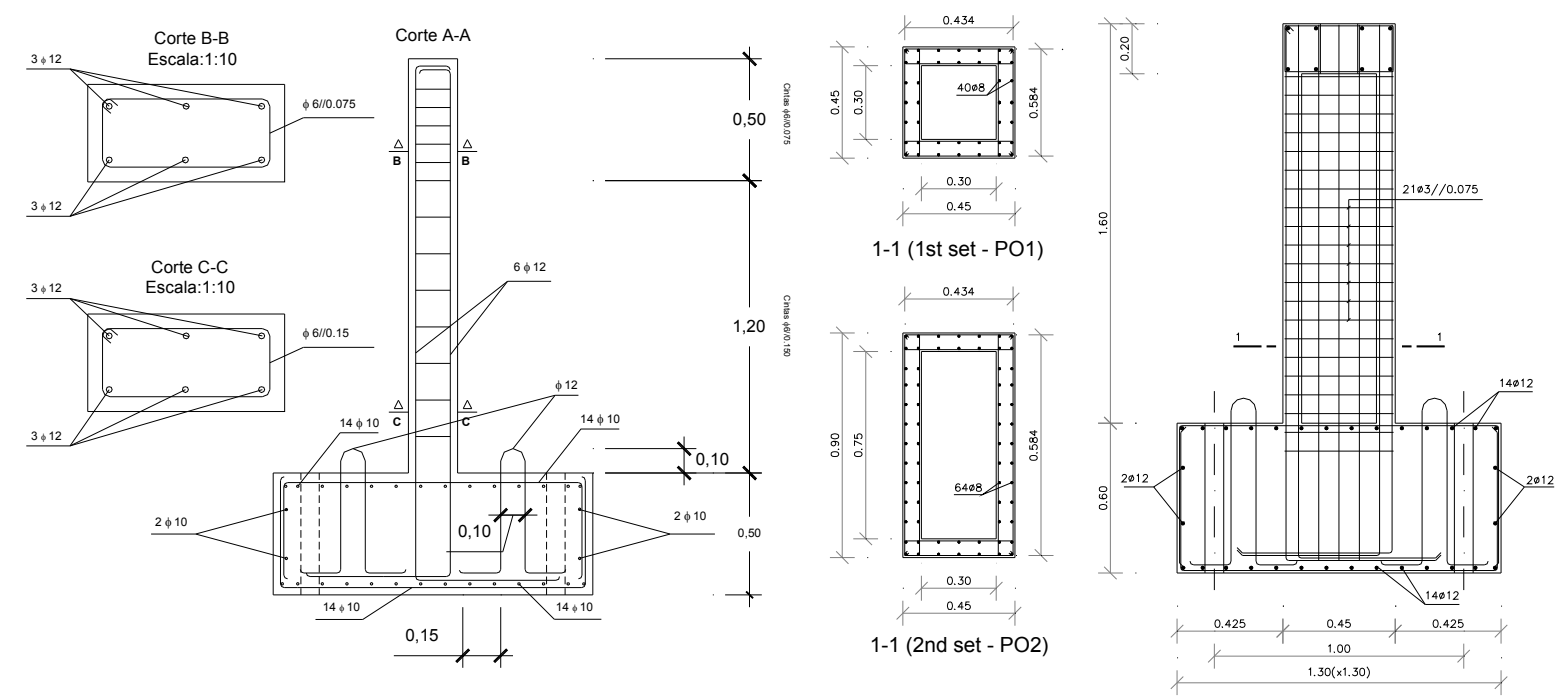

Figure 5: Rectangular section RC columns (full scale) and hollow section RC piers (1/4 scale).

For all the column specimens, three repetitive cycles were applied for several peak drift ratios, $\Delta / \mathrm{L}$, where $\Delta$ is the lateral displacement and $\mathrm{L}$ is the clear length of the column model measured between the bottom and the application point of the lateral force.

A comparison between the experimental cyclic results of the three columns is presented in Fig. 6. As can be seen, for specimen PA1-N2 and PA1-N3 (Fig. 6a), the results are quite close for the maximum forces achieved and globally for all the cyclic behaviour. In the case of specimen PA1-N2, buckling of longitudinal reinforcement was observed for a displacement of $+50 \mathrm{~mm}$, while for the opposite direction it was only observed at $-60 \mathrm{~mm}$. This fact justifies the observed asymmetric behaviour where the strength degradation is evident for displacements larger than $60 \mathrm{~mm}$ in the negative direction. Meanwhile, specimen PA1-N3 exhibited a noticeable symmetry since the buckling of the longitudinal bars started for a displacement of $50 \mathrm{~mm}$. As seen during the tests, and also after analysing the results, the buckling of the longitudinal reinforcement between the critical section (at the column base) and the first hoop drastically affects the column behaviour, which leads the fast strength degradation.

During the first tests an undesired problem occurred with the hydraulic system used to apply the axial load: the pressure that should remain constant was in fact increasing. The hydraulic system was designed to keep the oil pressure constant, in order to maintain the axial force constant as well. However, a deficient performance of the circuit has blocked the return of the oil from the vertical actuator therefore, the axial load increased during the cyclic displacement history, because the axial actuator was forced to remain in the same position when the 
top-end pier section was rotating and displacing. From pier PA1-N6 on, this problem was fixed and significant reduction on maximum forces was achieved [16].

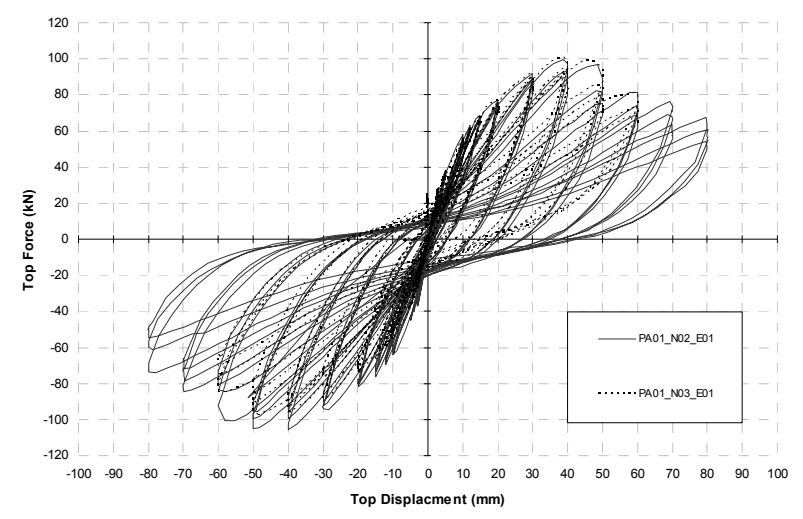

a) PA1-N2 and PA1-N3 ("as built")

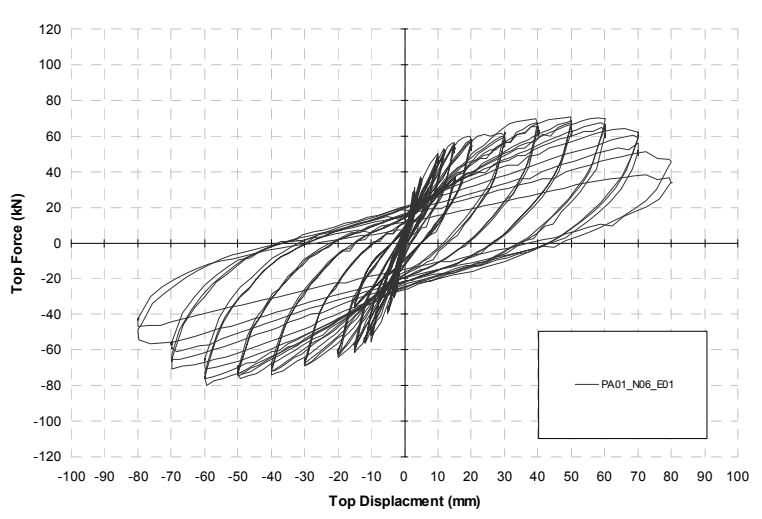

b) PA1-N6 ("as built")

Figure 6: Experimental cyclic results of columns.

With respect to the results of the hollow rectangular section RC piers, Fig. 7a shows the experimental responses in terms of top force-displacement diagrams of both piers PO2-N2 and PO2-N3, with different axial loads, $250 \mathrm{kN}$ and $440 \mathrm{kN}$ respectively. As expected, the pier with higher axial load (PO2-N3) shows larger initial stiffness and maximum forces. However, failure of both piers was reached for the first cycles of $25 \mathrm{~mm}$ amplitude (1.8\% drift), with visible shear failure mode and the shear lag effect.

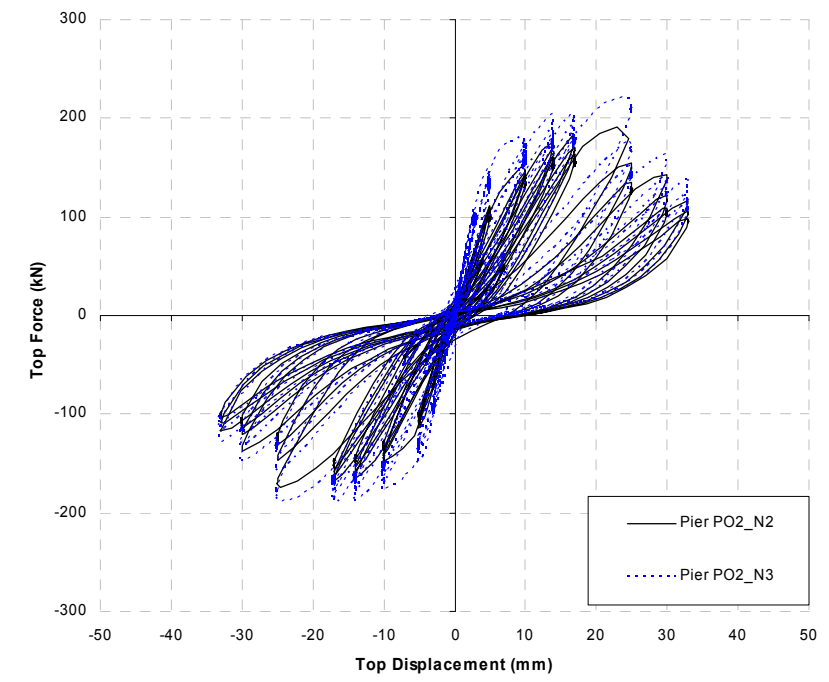

(a) Experimental comparison for PO2-N2 and PO2-N3

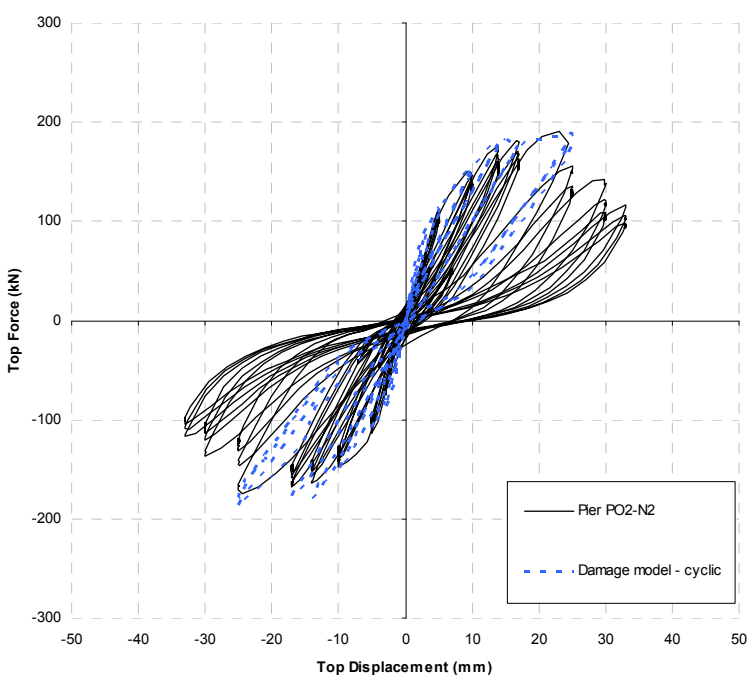

(b) Numerical analysis for pier PO2-N2

Figure 7: Experimental and numerical results comparison.

Additionally, a numerical simulation of these tests was also attempted. Numerical analysis of the structural members under cyclic loading was simulated using the CAST3M computer code [18], a general purpose finite element based program where a wide variety of nonlinear behaviour models are available and, particularly, a damage model developed at FEUP [19] and recently implemented in CAST3M [20], that has already proved to be suitable for seismic behaviour analysis of RC bridge piers [21]. Results of the numerical model for pier PO2$\mathrm{N} 2$ are included in Fig. 7b, see [22] for additional details. 


\section{FUTURE PERSPECTIVES FOR SEISMIC DESIGN}

According to modern structural codes, the seismic design of new structures, or the evaluation of the seismic performance of existing ones, can be performed using linear or nonlinear procedures. When linear procedures are adopted the "strength" of the structure is analysed, considering structural dynamic behaviour in terms of internal action effects and safety is checked by comparing demand at the member sections with their corresponding maximum available capacity, computed from the characteristic material properties scaled by the appropriate partial safety factor. Within the scope of nonlinear procedures, pushover analysis is proposed, which consists of a lateral force analysis procedure that considers nonlinear behaviour of the materials. The "strength" of the structure is essentially analysed in terms of displacement related parameters for which no safety format is clearly proposed.

With recent developments both in computational tools and in seismic numerical analysis, new perspectives for seismic design can be developed, where fully nonlinear dynamic analysis of the structures and an accurate seismic safety format can be coded.

Nowadays, the use of direct integration techniques for the solution of linear or nonlinear dynamic systems is available in many software codes and can be easily used for professional purposes. In fact, the use and interpretation of the results obtained from nonlinear dynamic analysis has the same degree of difficulty, or even lower, than that of nonlinear static (pushover) analysis. The only two key points that must be carefully defined are the seismic action and the constitutive laws of the materials. From the seismic action point of view a set of real or synthetic accelerograms, and an adequate scaling technique to be able to consider different intensities, should be provided. In the opinion of the authors, a technique for obtaining synthetic accelerograms matching a given response spectrum could be easily provided for professional purposes within the scope of a structural code. The definition of constitutive laws for the materials could be more controversial. However, considering the research performed during the last decade, either considering plastic hinges or fibre models for the numerical modelling of the structural elements, it seems possible to define simplified models depending on few material parameters that enable the simplified characterization of the cyclic behaviour of the most common structures, including hysteric behaviour, stiffness and strength degradation and pinching effects.

When nonlinear analyses are used the "strength" capacity of the structure is evaluated in terms of displacement related parameters, namely such as ductilities, chord rotation or inter-storey drifts. For such parameters, the safety levels that must be assured are not yet defined in a clear and generalized accepted way. However, it seems that efforts must be done in order to establish a format similar to the one used when other limit states are considered, defining characteristics values for the relevant parameters, ductilities, chord rotation or storey drifts, and partial safety factors in accordance. Alternatively, a direct evaluation of the collapse probability, for example in a manner such as the one presented in Section 3, could be easily performed in the context of nonlinear dynamic analysis. The additional data needed would be the probability distribution function of the seismic action, which could be established without great controversial (as it is already being done in the United States), and the probability density function for the capacity of the parameters selected for characterizing the seismic response of the structure.

Finally, a closing remark should be made about the difficulty of preparing the professional engineers for the use of these concepts. Despite the considerable advances in seismic design of structures over the past years, it still involves concepts with some degree of complexity, namely those regarding the adequate consideration of the dynamic behaviour of the structures involving nonlinear constitutive laws for the materials. As in the past, specialized and well prepared structural engineers are crucial for the sound application of either old or new concepts. In the context of moving forward to a seismic design based on nonlinear analysis, this new step does not seem to be more difficult than others done in the recent past of this young scientific area of earthquake engineering.

\section{ACKNOWLEGMENTS}

This paper reflects research activities carried out with the financial support of the Portuguese Foundation for Science and Technology, namely through the PhD grant of the sixth author (SFRH/BD/32820/2007), that is gratefully acknowledged. 


\section{REFERENCES}

[1] CEN, European Committee for Standardization (2004) Eurocode 8: Design of structures for earthquake resistance, Part 3: Assessment and retrofitting of buildings (final draft).

[2] CEN, European Committee for Standardization (2003) Eurocode 8: Design of structures for earthquake resistance, Part 1: General rules, seismic actions and rules for buildings.

[3] Borges, J.F. and Castanheta, M., Structural Safety Curso 101, 3ª Edition. 1982, Lisbon: LNEC.

[4] Costa, A.G., Seismic Analysis of Irregular Structures (in Portuguese) in FEUP. 1989, PhD Thesis; UP: Porto.

[5] Duarte, R.T., Oliveira, C.S., Costa, A.C., and Costa, A.G., A Non-linear Model for Seismic Analysis, Design and Safety Assessment of Reinforced Concrete Buildings, in Earthquake Damage Evaluation \& Vulnerability Analysis of Building Structures, A.Koridze, Editor. 1990, OMEGA Scientific.

[6] Romão, X., Delgado P., Guedes, J., Costa, A. e Delgado, R. (2005) Probabilistic Seismic Risk Assessment of Constructions. Proceedings of the "250th Anniversary of the 1755 Lisbon Earthquake" International Conference, Lisbon, Portugal.

[7] C.A.Cornell, F.Jalayer, R.O.Hamburger, and Foutch, D.A., The probabilistic basis for the SAC/FEMA steel moment frame guidelines. Journal of Engineering Mechanics, ASCE, 2000 128(4): p. 526-533.

[8] Pinto, P.E., Giannini, R., and Franchin, P., Seismic Reliability Analysis of Structures, ed. I.U.d.S.S.d. Pavia. 2004, Pavia: IUSS Press.

[9] Oliveira, C.S., Sousa, M.L., and Campos-Costa, A. Definition of Seismic Action in the Context of EC-8. Topics for Discussion. in 12th World Conference on Earthquake Engineering. 1999. Auckland, New Zealand.

[10] Costa, A., A Acção dos Sismos e o Comportamento das Estruturas (in Portuguese), in FEUP. 1993, Porto.

[11] Delgado, J.M., Azeredo, M., and M., D.R., Probability of failure estimation of current reinforced structures using the Latin Hypercube Sampling, in RISK ANALYSIS II, C.A. Brebbia, Editor. 2000, Wit Press: Boston, Southampton. p. 105-114.

[12] McKay, M. D., Beckman, R. J. and Conover, W. J. (1979) A comparison of three methods for selecting values of input variables in the analysis of output from a computer code, Technometrics, 21, pp.239-245.

[13] Romão, X., Delgado, R., Guedes, J. and Costa, A. (2007) A seismic safety assessment study for the limit states of existing structures according to the EC $8,7^{\circ}$ Congresso Nacional de Sismologia e Engenharia Sísmica - Sísmica 2007, Porto, Portugal.

[14] Pinho, R., Selective retrofitting of RC structures in seismic areas. 2000, Imperial College of Science and Technology: London.

[15] Varum, H., Seismic assessment, strengthening and repair of existing buildings. 2003, FEUP: Porto.

[16] Pavese, A., Bolognini, D., and Peloso, S., FRP seismic retrofit of RC square hollow section bridge piers. Journal of Earthquake Engineering, 2004. 8(1 SPEC. ISS.): p. 225-250.

[17] Delgado, P., Rodrigues, V., Rocha, P., Santos, M., Arêde, A., Pouca, N.V., Costa, A., and Delgado, R. (2005) Experimental Tests on Seismic Retrofit of RC Columns. 1st USA-PORTUGAL International Workshop on Earthquake Engineering and FRP Strengthening Techniques, 11-13 July Lamego, Portugal.

[18] CEA (2003) Manuel d'utilisation de Cast3m, Commissariat à l'Énergie Atomique. Pasquet, P.,

[19] Faria, R., Oliver, J., and Cervera, M. (1998) A strain based plastic viscous damage model for massive concrete structures. International Journal of Solids and Structures, 35(14), 1533-1558

[20] Costa, C., Pegon, P., Arêde, A., and Castro, J. (2005) Implementation of the Damage model in Tension and Compression with Plasticity in Cast3m. Report EUR, ISPC, CEC, JRC, Ispra (VA), Itália, (publication stage)

[21] Faria, R., Pouca, N.V., and Delgado, R., Simulation of the Cyclic Behaviour of R/C Rectangular Hollow Section Bridge Piers via a Detailed Numerical Model. Journal of Earthquake Engineering, 2004. 8(4): p. 124.

[22] Delgado, P., Rocha, P., Pedrosa, J., Arêde, A., Pouca, N.V., Santos, M., Costa, A., and Delgado, R. (2007) Retrofitting of Bridge Hollow Piers with CFRP. ECCOMAS Thematic Conference on Computational Methods in Structural Dynamics and Earthquake Engineering, 13-16 July Rethymno, Crete, Greece. 